\title{
The immediate effects of breathing with oscillated inspiratory and expiratory airflows on secretion clearance in intubated patients with cervical spinal cord injury
}

\author{
Sujittra Kluayhomthong ${ }^{1} \cdot$ Chulee Ubolsakka-Jones $^{1} \cdot$ Pornanan Domthong $^{2} \cdot$ Wipa Reechaipichitkul ${ }^{3}$. \\ David A. Jones ${ }^{4}$
}

Received: 24 August 2018 / Revised: 27 October 2018 / Accepted: 5 November 2018 / Published online: 20 November 2018

(c) International Spinal Cord Society 2018

\begin{abstract}
Study design: A prospective, randomized crossover trial.

Objectives: To evaluate the efficacy of the combination of incentive spirometry with oscillation (OIS) and positive expiratory pressure with oscillation (OPEP) to promote secretion clearance in intubated patients with cervical spinal cord injury.

Setting: Spinal cord unit, tertiary care hospital, North East Thailand.

Methods: Thirteen intubated patients (C4-7, AIS score C) with secretion retention performed three interventions randomly allocated on consecutive days, a Sham deep breathing, OPEP and OPEP + OIS breathing exercise. Secretions were collected by sterile suction for $3 \mathrm{~h}$ before, and $3 \mathrm{~h}$ after, each intervention and wet weight recorded. Cardiopulmonary parameters were measured before and after each intervention.

Results: The median (IQR) secretion wet weight pre-intervention was $2.61 \mathrm{~g}(2.21,3.85)$ and in the $3 \mathrm{~h}$ after Sham there was an increase of $1.97 \mathrm{~g}(0.6,3.6)$. The increase after OPEP was $2.67 \mathrm{~g}(1.7,3.9)$ and after OPEP + OIS, $4.28 \mathrm{~g}(2.4,6.7)$; all the increases being significant $(\mathrm{p} \leq 0.007)$. The clearance after OPEP and OPEP + OIS were both greater than Sham while OPEP + OIS was greater than OPEP $(\mathrm{p} \leq 0.019)$. There were no significant changes in cardiopulmonary measures following any intervention or when compared between interventions.

Conclusions: Deep breathing with an oscillated and humidified air flow in a combination of OIS + OPEP more than doubled secretion clearance and was more effective than OPEP or Sham deep breathing. There were no adverse effects of the procedures which were well tolerated by the patients and may be used to complement existing methods for secretion clearance.
\end{abstract}

Chulee Ubolsakka-Jones

Joneschulee@gmail.com

1 School of Physical Therapy, Faculty of Associated Medical Sciences, Khon Kaen University, Khon Kaen, Thailand

2 Department of Medicine, Khon Kaen Hospital, Khon Kaen, Thailand

3 Department of Medicine, Faculty of Medicine, Khon Kaen University, Khon Kaen, Thailand

4 School of Healthcare Science, Manchester Metropolitan University, Manchester, UK

\section{Introduction}

For patients with cervical spinal cord injury (CSCI), respiratory complications are debilitating, costly and lifethreatening, with a high incidence of morbidity (36\%) and mortality (83\%) [1]. Weakness or paralysis of the respiratory muscles, together with intubation, which is required in nearly all of cases of high level CSCI, results in expiratory flow bias and cough impairment, excessive bronchial secretion and decreased mucociliary activity, all of which leads to a failure to properly clear airway secretions [2-4]. Accumulating secretions can result in lung infection, alveolar hypoventilation, increased airway resistance and work of breathing [5-10]. Immobility in patients with mechanical ventilator dependence is an additional factor 
leading to lung infection and atelectasis, significant causes of mortality and morbidity $[6,11]$.

Accordingly, the aggressive management of secretion clearance is the cornerstones of early treatment to prevent respiratory complications, improve clinical care and reduce healthcare costs [12]. Manual chest physical therapy techniques are commonly used to promote clearance but this is often difficult within the constraints of the ICU and, currently, there are no studies demonstrating their efficacy in clearing secretions for patients with tetraplegia [13]. Other techniques involve manual assisted cough and cough assist devices that can be used with both intubated and nonintubated patients.

Factors which encourage secretion clearance include oscillation of the airflow, increasing lung volume to open the airway and humidification of the inspired air [11, 14, 15]. Slow expiration against a positive expiratory pressure (PEP) has been documented to help prevent airway collapse during expiration $[16,17]$ and a combination of PEP and oscillation, in devices such as Flutter, have been reported to increase secretion clearance in cases of bronchiectasis $[18,19]$.

We have previously described the use of a simple threshold inspiratory breathing device to help with secretion clearance in mechanically ventilated patients [10], although none had SCI. When using the device, inspiration is against an adjustable head of water and as the air bubbles through the water the flow is both oscillated and humidified (oscillating incentive spirometry; OIS). The bubbles also give auditory feedback that can be used to guide the length, and therefore depth, of inspiration. The device can also be used to provide an expiratory pressure where, again, the airflow is oscillated by bubbling through the water (oscillating positive expiratory pressure; OPEP). By connecting the two devices with a suitable valve it is possible to provide both OIS on the inspiratory side and OPEP on the expiratory side. Patients with incomplete CSCI who can inspire actively and perform a degree of forced expiration may therefore benefit from OPEP or a combination of OIS and OPEP to improve secretion clearance. The purpose of the present study was, therefore, to evaluate the efficacy of these interventions.

\section{Methods}

Thirteen intubated patients with cervical cord injury (C4C7) admitted to the Spine Unit of the Medical ICU of Khon Kaen Hospital, were recruited after being referred to physical therapy for secretion clearance. The time since injury varied between 9 to 402 days (median 23 days). Inclusion criteria were: 1) intubation and hyper-secretion defined as the need for tracheal suctioning $<2 \mathrm{~h}$ [8] and secretion volume at least $1 \mathrm{ml} / \mathrm{h}[20]$; 2) for patients who breathed
Table 1 Patient characteristics

\begin{tabular}{|c|c|c|}
\hline \multicolumn{2}{|l|}{ Measure } & \multirow{2}{*}{$\frac{\text { Value }}{12 / 1}$} \\
\hline Number & $\mathrm{M} / \mathrm{F}$ & \\
\hline Age & years mean (range) & $51(28-70)$ \\
\hline Weight & kg mean $(\mathrm{SD})$ & $61(10)$ \\
\hline Height & cm mean (SD) & $168(7)$ \\
\hline BMI & kg.m ${ }^{-2}$ mean $(\mathrm{SD})$ & $21(3)$ \\
\hline Level of injury & range & $\mathrm{C} 4-7$ \\
\hline AIS score & & $\mathrm{C}$ \\
\hline APACHE & mean $(\mathrm{SD})$ & $14(2)$ \\
\hline Time since injury & days median (IQR) & $23(21,30)$ \\
\hline "a Spontaneous breathing & Number patients (\%) & $3(23)$ \\
\hline \multicolumn{3}{|l|}{${ }^{\mathrm{b}}$ Mechanical ventilation } \\
\hline $\begin{array}{l}\text { - PC- AC, PIP } 16 \mathrm{cmH}_{2} \mathrm{O} \text {, } \\
\text { Ti } 1.0 \mathrm{~s}\end{array}$ & Number patients (\%) & $1(8)$ \\
\hline - PSV, PS 8-10 cm $\mathrm{H}_{2} \mathrm{O}$ & Number patients (\%) & $7(54)$ \\
\hline - SIMV & Number patients (\%) & $2(16)$ \\
\hline RSBI & $\begin{array}{l}\text { Breaths.min }{ }^{-1} \cdot \mathrm{L}^{-1} \\
\text { mean }(\mathrm{SD})\end{array}$ & $46.8(12.6)$ \\
\hline Spontaneous VT & ml mean (SD) & $424(58)$ \\
\hline Spontaneous SVC & ml median (IQR) & $\begin{array}{l}594(527, \\
817)\end{array}$ \\
\hline Spontaneous VE & L.min ${ }^{-1}$ mean $(\mathrm{SD})$ & $8.3(0.7)$ \\
\hline Respiratory rate & $\begin{array}{l}\text { Breaths.min }{ }^{-1} \text { mean } \\
\text { (SD) }\end{array}$ & $19.0(2.9)$ \\
\hline $\mathrm{SpO}_{2}$ & $\begin{array}{l}\text { \% saturation mean } \\
(\mathrm{SD})\end{array}$ & $99.4(0.6)$ \\
\hline Heart rate & Beat.min ${ }^{-1}$ mean (SD) & $72(6.5)$ \\
\hline
\end{tabular}

Note: Cardiorespiratory data are the average of measures taken immediately prior to each of the three interventions for each subject

$B M I$ Body Mass Index, AIS ASIA impairment scale, APACHE Acute Physiology and Chronic Health Evaluation score, $P C$ - $A C$ Pressure control-assist control, $P I P$ peak inspiratory pressure, $T i$ inspiratory time, $P S V$ pressure support ventilation, PS pressure support, SIMV synchronized intermittent mandatory ventilation, $V T$ Tidal Volume, SVC Slow Vital Capacity, VE Minute ventilation, RSBI Rapid Shallow Breathing Index, $\mathrm{SpO}_{2}$ Pulse oxygen saturation

${ }^{\text {a}} \mathrm{PEEP} 5 \mathrm{cmH}_{2} \mathrm{O}$ and $\mathrm{FiO}_{2} 0.4$ were set for all patients on mechanical ventilation

${ }^{\mathrm{b}}$ Spontaneous breathing with T-piece, collar mask, oxygen flow 2-10 L. min $^{-1}$

with mechanical ventilation, the positive end expiratory pressure should be lower than $6 \mathrm{~cm} \mathrm{H}_{2} \mathrm{O}$;3) stable cardiopulmonary function and positive fluid balance for at least 2 days before data collection; 4 ) the ability to breathe spontaneously for $2 \mathrm{~min}$ without developing hypoxemia, and 5) good comprehension and co-operation such as being able to make maximal efforts on command. Exclusion criteria were massive hemoptysis, untreated pneumothorax, acute myocardial infarction (with angina chest pain), major arrhythmia or high intracranial pressure (ICP $>20 \mathrm{~mm} \mathrm{Hg}$ ). 


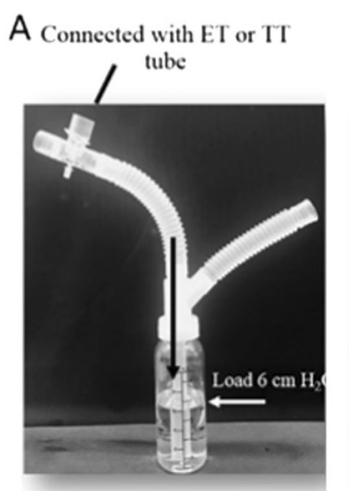

OPEP intervention

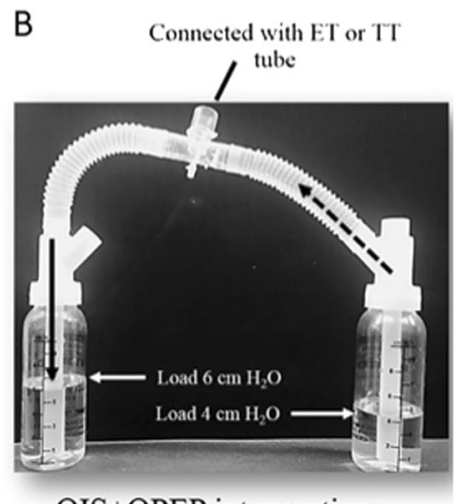

OIS+OPEP intervention
Fig. 1 The breathing device showing the connection to the endotracheal or tracheostomy tube via a one-way valve. a the arrangement for breathing in the OPEP intervention. b the connections used for OIS + OPEP. For the Sham intervention, the connection was as in OIS + OPEP except the bottles did not contain any water. OPEP, oscillated positive expiratory pressure breathing; OIS, oscillated incentive spirometry

Physical and cardiopulmonary characteristic of patients (Table 1) were obtained from medical records on the day before the first data collection. A rapid shallow breathing index (RSBI) was calculated as breathing rate/tidal volume (breaths. $\min ^{-1} \cdot \mathrm{L}^{-1}$ ).

\section{Procedure}

The study was a crossover trial in which the treatment order was randomized using a Latin square $(3 \times 3)$. Sputum was collected in a routine manner by nurses who were not involved with the study. The patients were studied at the same time in the morning with an overnight washout between interventions. The patients received routine chest physiotherapy for at least 2 days before data collection, which continued after the end of data collection.

The arrangement of devices used for the breathing exercise are shown in Fig. 1 and was based on the threshold incentive spirometry device (BreatheMAX) described previously [10]. For OPEP breathing, the tube from the patient opened under water (Fig. 1a), providing an expiratory resistance and oscillation of the air stream. For the combined OPEP + OIS intervention a second bottle was added with a one-way valve so that during inspiration air was drawn into the bottle through the inlet tube opening under water, so humidifying and oscillating the inspired air (OIS). Expired air then passed through the other bottle, as for OPEP breathing. The sound of bubbles when breathing with OIS and OPEP can be used to provide feedback to guide slow and deep breathing. For the Sham breathing, the patient used the same arrangement as for OPEP + OIS but with no water in either bottle so there was no oscillation or humidification of the air.
The patients performed active breathing exercise using the device in the half lying (30 degree) position. For the OPEP intervention, patients performed deep breathing, inspiring with no load and breathing out with prolonged steady flow of $0.2{\mathrm{~L} . \mathrm{s}^{-1}}^{-1}$ to FRC against an expiratory load of $6 \mathrm{~cm} \mathrm{H}_{2} \mathrm{O}$. For the OIS + OPEP intervention, the patients performed slow deep breathing against a water pressure load of $4 \mathrm{~cm} \mathrm{H}_{2} \mathrm{O}$ and a flow rate of approximately $0.4 \mathrm{~L} . \mathrm{s}^{-1}$. They were encouraged to sustain maximal inspiration for $3 \mathrm{~s}$ at the end of the inspiratory phase then to breathe out with prolonged steady flow to FRC, as for OPEP. The Sham intervention consisted of the patient undertaking the intervention as for OIS + OPEP but with no oscillation or humidification of the air flow. Before data collection, the participants received instruction on the breathing exercise and use of the device.

The study protocol began at 07.30 a.m. with suction to clear the airway. Secretions were then collected by suction over the next $3 \mathrm{~h}$ with the last suction at 10.30 before the start of the intervention. The patient was disconnected from the ventilator and the tracheostomy or endotracheal tube connected to the device (Fig. 1) and the patient performed 10 sets of active breathing with 10 breaths/set. There was a rest of at least $1 \mathrm{~min}$ between sets with the patient reconnected to the ventilator. The patients received one intervention a day with the 3 interventions carried out on consecutive days, allocated in a random order.

Heart rate $(\mathrm{HR})$, respiratory rate $(\mathrm{RR})$ and oxygen saturation $\left(\mathrm{SpO}_{2}\right)$ were monitored during the interventions. The interventions would have been stopped if the RR had been $>30$ breaths/min, $\mathrm{HR}>120$ beats $/ \mathrm{min}, \mathrm{SpO}_{2}<90 \%$ or paradoxical breathing developed, but none of these eventualities occurred.

\section{Outcome measures}

Airway secretions were collected by nursing staff, who were blinded to the interventions, with a sterile suction technique via the tracheostomy or endotracheal tube with no addition of saline or sterile water. Secretions were collected at $1-2 \mathrm{~h}$ intervals, or more frequently if necessary, over the $3 \mathrm{~h}$ before and after each intervention. Secretions were sucked into a $25 \mathrm{ml}$ extractor (Hangzhou Medtec Medical Devices co, Ltd, China), sealed and kept on ice until the weight was recorded (Metter Toledo, PL202S balance, measuring to $0.01 \mathrm{~g}$ ).

Spontaneous minute ventilation $(\mathrm{Ve})$, tidal volume $(\mathrm{Vt})$ and slow vital capacity (SVC) were measured using a Wright respirometer (SpireHealth, HS4710s, England) while the patient was disconnected from the ventilator and in the Semi-Fowler position (head up 30-45 degree). The Wright respirometer was connected via a bacterial filter and $15 \mathrm{~cm}$ corrugated tube to the ET or TT tube of patient. For 


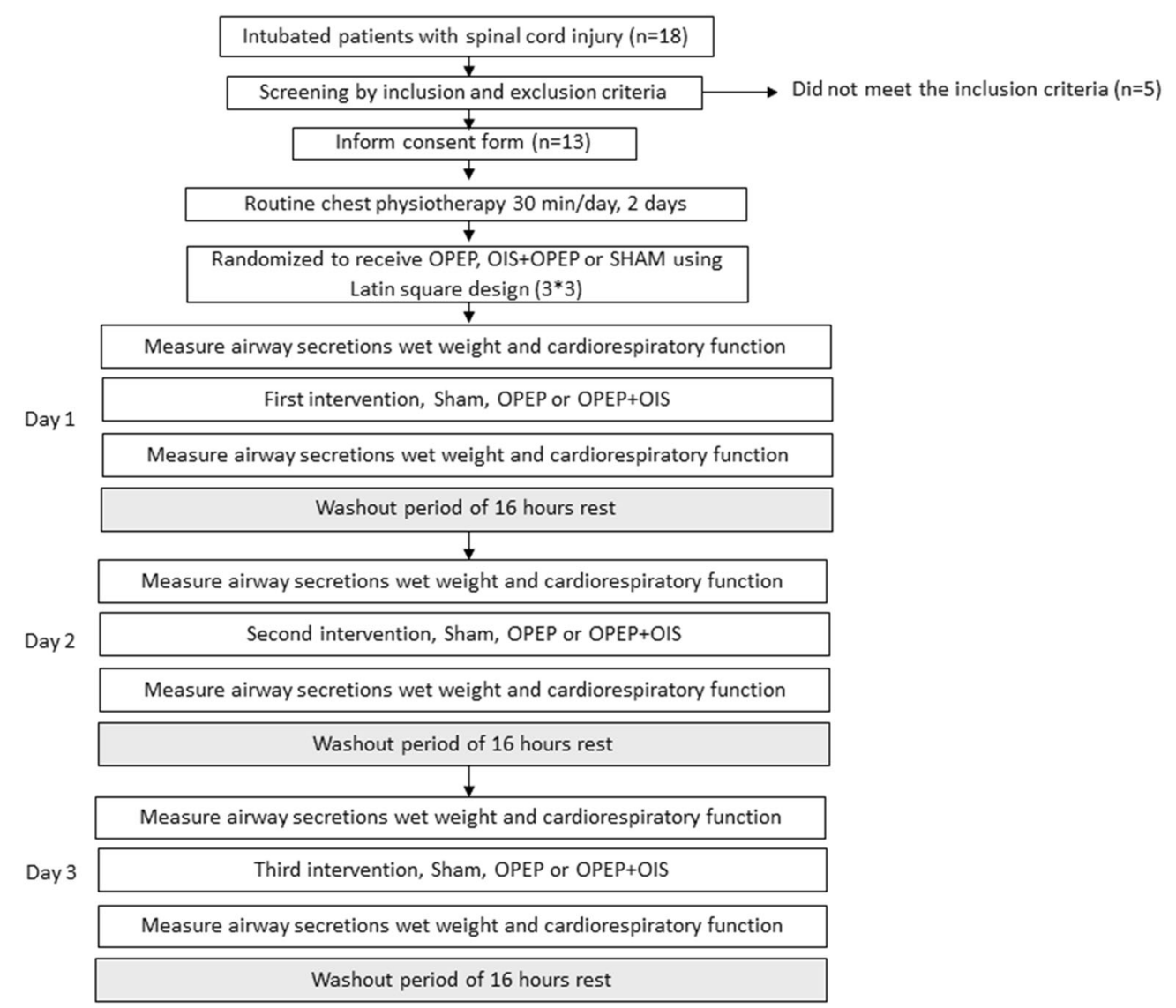

Fig. 2 Design and flow of participants through the trial

SVC, the patients were instructed to inspire maximally follow by maximum exhalation. SVC, Vt and RR were measured before each intervention with Vt and RR assessed again immediately after the intervention.

After each intervention, and once returned to the ventilator, where necessary, the patient was asked to indicate how difficult they found the breathing exercises in terms of physical effort (RPE) and sensation of dyspnea (RPB), using Borg CR10 scales. Patients were questioned about any adverse effects, such as dizziness, and their selfconfidence when disconnected from the ventilator.

Oxygen saturation and heart rate were measured with a finger pulse oximeter (Nihon Kohden-life scope ${ }^{\circ}$ ) and the spontaneous breathing frequency were measured for $1 \mathrm{~min}$ and reported as a rate before and after each intervention. The study was prospectively registered as a clinical trial; registration number: NCT02553200.

\section{Statistical analyses}

The data are presented as the mean and standard deviation (SD) or median (interquartile range, IQR) as appropriate. Since most of the outcome measures were not normally distributed, data for the difference in secretion clearance between the $3 \mathrm{~h}$ before and after intervention were subject to bootstrap analysis [21, 22] and are presented as mean and $95 \% \mathrm{CI}$; difference between interventions were analyzed the same way. Statistical significance was assessed with Student's $T$ test with Bonferoni correction for multiple comparisons. All data were analyzed using SPSS 20.0.

\section{Results}

Eighteen patients were initially assessed for inclusion in the study but 5 were excluded, the main reason being unable to breathe spontaneously for $2 \mathrm{~min}$ without developing hypoxemia $(N=4)$. The sequence of testing for the remaining 13 subjects is shown in (Fig. 2) and their physical characteristics, mechanical ventilator use and cardiopulmonary measures, taken before intervention, are shown in Table 1.

All 13 patients had partial SCI lesions but with no evidence of diaphragm denervation. Ten of the patients had X-ray evidence of lung pathology; 5 had, or had had, 


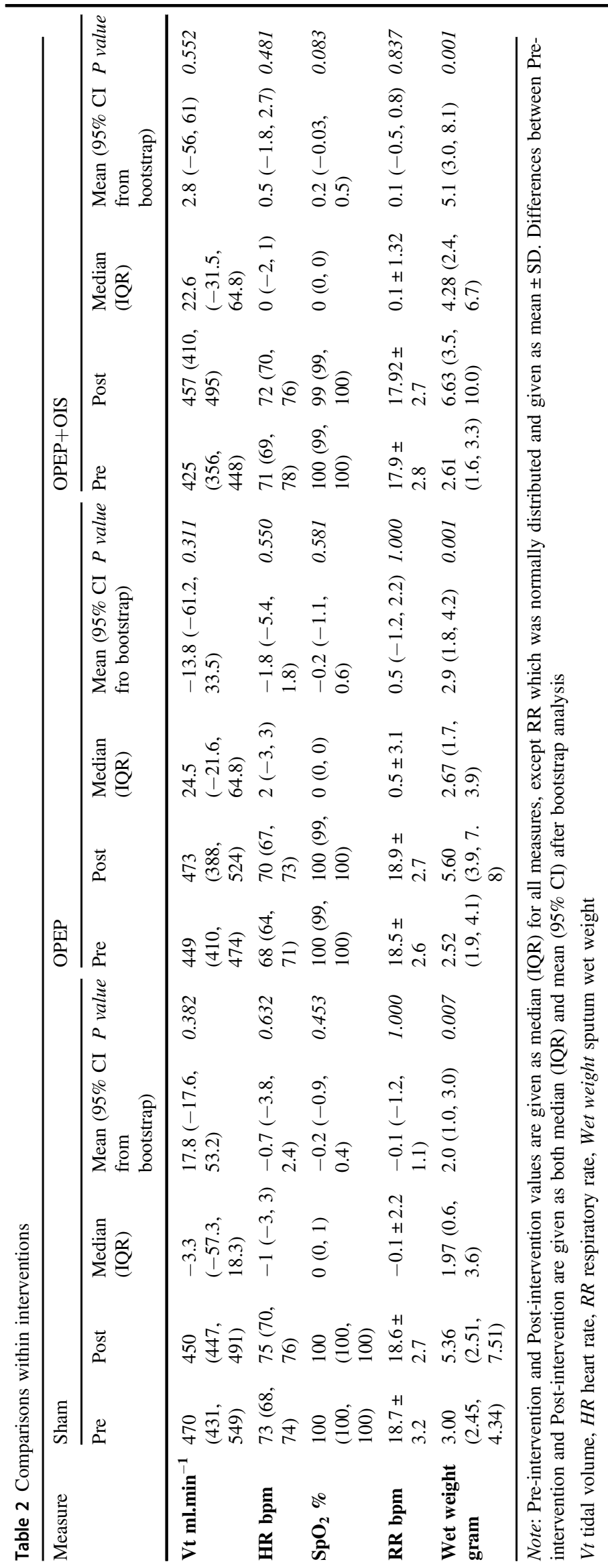

pneumonia and a further 5 had atelectasis, 2 with evidence of infiltration but all were in a stable state; the cardiopulmonary values measured before intervention were consistent over the three days of testing. Tidal volumes were surprisingly normal, but it is notable that tidal volume constituted a very high proportion of the SVC which may have been experienced as a high work of breathing and contributed to the difficulty some patient had with weaning. Nevertheless, all were able to breathe spontaneously for at least $2 \mathrm{~min}$. Respiratory rates were slightly raised and RSBI was consistent with the patients being comfortable breathing spontaneously for a few minutes. Patients had no difficulties with the interventions and there were no adverse events.

Data for the various outcome measures preintervention and post-intervention are given in Table 2 . Figure $3 \mathrm{a}$ shows the sputum collected in the $3 \mathrm{~h}$ before and $3 \mathrm{~h}$ following each of the interventions. The median (IQR) secretion wet weight in the $3 \mathrm{~h}$ before the interventions was $2.61 \mathrm{~g}(2.21,3.85)$ and this increased following each of the interventions. The differences in secretion wet weight between pre-intervention and postintervention are shown in Fig. 3b, and in each case, including the Sham deep breathing, there was a significant increase in secretion clearance as a result of the intervention (see also Table 2). Differences between interventions are shown in Table 3. For secretion wet weight, OPEP + OIS was found to be more effective than OPEP and Sham, while OPEP was more effective than Sham.

Cardiopulmonary measures were not changed by any of the interventions and remained within acceptable and safe ranges (Table 2) and there were no differences between interventions (Table 3).

On questioning, all patients found the breathing exercises to be comfortable and felt confident being detached from the ventilator during the intervention. Two patients reported slight dizziness following the OPEP intervention but this resolved rapidly on returning to the ventilator. At the end of each intervention and, where necessary, returning to the ventilator, the patients were asked about their sense of effort (RPE) and dyspnea (RPB). Although asked about these sensations separately the patients gave the same score for both. The Sham intervention was rated (median and IQR) at $2(1,3)$; OPEP at $3(2,3)$, while there was a slightly higher range for OIS + OPEP of $3(2,4)$. Although the numbers were not sufficient to test statistically, there were no obvious differences in the responses or perceptions of the majority of patients who were dependent, to some degree, on mechanical ventilation compared with the three who were able to breathe independently. 


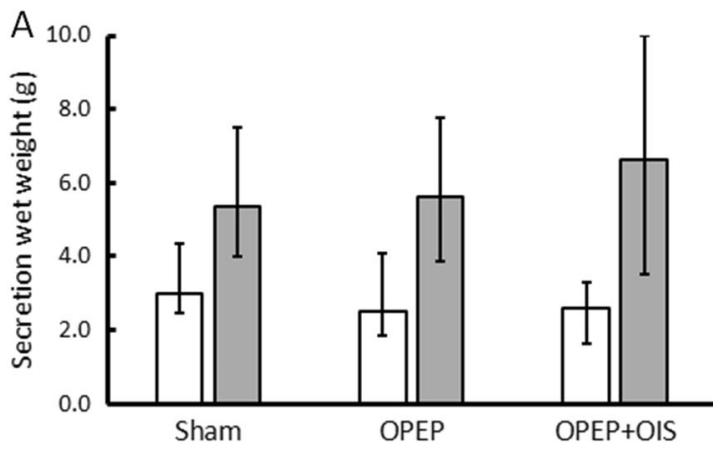

Fig. 3 Secretion clearance. a Secretions cleared by suction in the $3 \mathrm{~h}$ before (open bars) and the $3 \mathrm{~h}$ following the intervention (filled bars); data are median and IQR. b Increase in secretion clearance from pre-

\section{Discussion}

Any impairment of respiratory muscle function as a result of SCI can lead to low lung volume, atelectasis and accumulation of secretions in the lung which increases the work of breathing and bring serious risk of infection. Intubation and mechanical ventilation, while essential for life support, may also exacerbate the accumulation of secretions as a result of the impaired ciliary transport and inability to cough $[8,10$, 23]. It is important, therefore, to find ways of increasing secretion clearance so as to improve the care and clinical outcome for patients with high level SCI [12].

The present study evaluated two potential methods for increasing clearance (Fig. 1) based on a simple threshold oscillating incentive spirometer device (OIS). We have previously used the device to successfully improve secretion clearance in intubated and ventilated patients who had limited SVC, similar to the SCI patients studied here [10]. An increase in secretion clearance of $4 \mathrm{~g}$ has been suggested to be clinically important [24] and this was achieved with the OPEP + OIS intervention, yielding a median increase of $4.28 \mathrm{~g}$.

All the patients had partial CSCI (AIS score C). Three patients did not require mechanical ventilation but, although able to breathe spontaneously, they did not have sufficient expiratory muscle strength to adequately cough and clear secretions. The other 10 patients required mechanical ventilator support but were confident enough to undertake the spontaneous breathing interventions. Deep breathing by itself, as in the Sham intervention, increased secretion clearance and this procedure is probably similar to the mechanical insufflation used by Pillastrini and colleagues [25] in that it increases lung volume and opens up the airway allowing better transport of secretions, although those authors did not measure actual secretion clearance.

Adding an expiratory resistance with oscillation, as with the OPEP intervention, has the effect of generating a positive pressure and slowing expiration which helps prevent

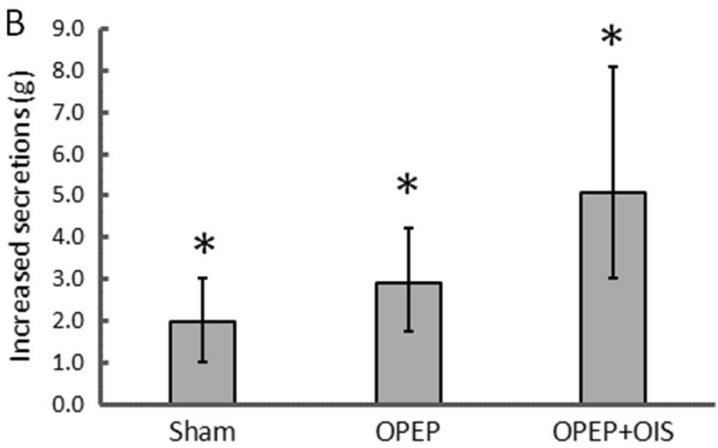

intervention to post-intervention; data are mean and 95\% CI (after bootstrap analysis). Asterisks (*) indicates significant increases

airway collapse, while oscillation of the airflow, which is thought to be at a similar frequency to that of the beating cilia, may also assist in secretion transport [14]. Passive treatment interventions such as high frequency chest wall oscillation and intrapulmonary percussive ventilation have also been suggested to improve secretion clearance [26-28].

The consequence of the OPEP intervention was to significantly increase secretion clearance (Fig. 3a) relative to the pre-intervention value. This conclusion is similar to reports of improved clearance in patients with bronchiectasis using the Flutter device [18, 19] which also provides PEP and oscillation. However, significantly greater benefits were seen when adding a resistance to the inspiratory side with the OPEP + OIS intervention. The oscillation of the whole breathing cycle, together with humidification of the inspired air, may have been the reason the combination of OPEP + OIS was more effective in clearing secretions than OPEP alone (Table 3). There is, however, one other factor which may have played a role. The sound of air bubbling through the water on the inspiratory side provides good feed-back both for the patient and the therapist encouraging a long and deep breath. As discussed above, deep breathing and opening of airways is one of the important factors considered to help secretion clearance.

For a clinical intervention to become part of routine treatment it must be safe and acceptable to the patients. There were no adverse effects of any of the interventions with heart rate, respiratory rate and $\mathrm{SpO}_{2}$ all remaining constant and within normal limits (Table 2). There was, initially, concern that the inspiratory $\left(4 \mathrm{~cm} \mathrm{H}_{2} \mathrm{O}\right)$ and expiratory $\left(6 \mathrm{~cm} \mathrm{H}_{2} \mathrm{O}\right)$ loads might be too much for the patients but, in practice, they were all able to cope and reported the effort, and dyspnea, to be around 3 using a Borg scale of 0-10. The combined OPEP + OIS was perceived to be slightly more difficult with a range of values from 2-5 compared with a range of 1-4 for Sham and OPEP. Values of 5 or less would normally be taken to 
Table 3 Comparisons between interventions

\begin{tabular}{|c|c|c|c|c|}
\hline & Between intervention & Median (IQR) & Mean (95\%CI from bootstrap) & $P$-value \\
\hline \multirow[t]{3}{*}{$\mathrm{Vt} \mathrm{ml} \cdot \min ^{-1}$} & OPEP + OIS vs. OPEP & $12.4(-8.9,53.4)$ & $16.6(-56.1,89.4)$ & 0.638 \\
\hline & OPEP + OIS vs. Sham & $4.4(-12.1,62.2)$ & $14.9(-60.6,90.5)$ & 0.480 \\
\hline & Sham vs. OPEP & $48.0(-11.3,81.8)$ & $31.6(-29.8,93.1)$ & 0.182 \\
\hline \multirow[t]{3}{*}{ HR bpm } & OPEP + OIS vs. OPEP & $-1.0(-5.0,2.0)$ & $2.2(-1.7,6.2)$ & 0.307 \\
\hline & OPEP + OIS vs. Sham & $-1.0(-3.0,2.0)$ & $-1.2(-4.0,1.7)$ & 0.479 \\
\hline & Sham vs. OPEP & $-1.0(-4.0,4)$ & $1.1(-3.1,5.2)$ & 0.875 \\
\hline \multirow[t]{3}{*}{$\mathrm{SpO}_{2} \%$} & OPEP + OIS vs. OPEP & $0(0,0)$ & $0.5(-0.6,1.5)$ & 0.416 \\
\hline & OPEP + OIS vs. Sham & $0(-1,0)$ & $-0.5(-1.2,0.3)$ & 0.222 \\
\hline & Sham vs. OPEP & $0(-1,1)$ & $0.00(-1.0,1.0)$ & 0.722 \\
\hline \multirow[t]{3}{*}{ RR bpm } & OPEP + OIS vs. OPEP & $0.4 \pm 2.6$ & $0.4(-1.2,1.9)$ & 1.000 \\
\hline & OPEP + OIS vs. Sham & $0.2 \pm 0.4$ & $0.2(-1.3,1.6)$ & 1.000 \\
\hline & Sham vs. OPEP & $0.5 \pm 4.5$ & $0.5(-2.2,3.2)$ & 1.000 \\
\hline \multirow[t]{3}{*}{ Wet weight gram } & OPEP + OIS vs. OPEP & $1.35(0.60,1.79)$ & $2.13(0.2,4.04)$ & 0.006 \\
\hline & OPEP + OIS vs. Sham & $2.29(0.52,4.46)$ & $3.07(0.8,5.3)$ & 0.006 \\
\hline & OPEP vs. Sham & $0.56(0.00,1.92)$ & $0.94(0.2,1.7)$ & 0.019 \\
\hline
\end{tabular}

Differences between interventions are given as both median (IQR) and mean (95\% CI) after bootstrap analysis, except for RR where the data are all means

$V t$ tidal volume, $H R$ heart rate, $R R$ respiratory rate, Wet weight sputum wet weight indicate that a procedure, such as used here, is acceptable for general use with patients.

Clearing secretions might be expected to improve lung function but no significant change was observed in any of the measured parameters following any of the interventions (Table 2). However, improvement following a single intervention are likely to be small and it is possible that regular use of the combined OPEP + OIS could improve lung function. It has been shown that glossopharyngeal breathing training for lung insufflation over an 8 week period improved lung function and increased chest expansion [29] and a randomize control trial of the effect of air staking on pulmonary function [30] showed significant increases of FVC after training for 6 weeks.

The purpose of the inspiratory and expiratory loads used here were to set suitable flow rates and generate airflow oscillation within the range of ciliary beating frequency. However prolonged use of the OIS + OPEP device would also provide a training stimulus for the respiratory muscles and a meta-analysis of the effects of respiratory muscle training on pulmonary function in tetraplegia [31] concluded that training increases respiratory muscle strength, function and endurance.

There are a number of limitations to this study, larger subject numbers are always valuable, but the major addition to any future study would be to follow the use of the intervention over a period of weeks or months to evaluate the clinical outcomes in terms of preventing infections, improving lung function and weaning and the duration of ICU stay. Neither the investigator or patients were blinded to the interventions but, given the nature of the interventions, this would be difficult to achieve. However, importantly, the nursing staff responsible for suctioning the patients were blinded to the intervention used. Allocation was not concealed but while concealment is an important factor when patients are allocated to treatment or nontreatment groups, this is not a concern in cross-over studies where all the patients receive all the treatments, or interventions. The only concern might be that the treatment order could have some effect, but this seems most unlikely in the present study and the Latin Square design ensured that the treatment order was randomized. The cardiopulmonary parameters were measured by one of researchers who was not blinded. In practice it would be very difficult for the person making the cardiopulmonary measurements to be blinded to the intervention since there was very limited time between the end of the intervention, suction, if need be, and making the lung function measurements, before the patient returned to the ventilator. There is no suggestion of any change in the cardiopulmonary variables (Table 2) and it is most unlikely that having a blinded observer would change this conclusion. Measuring SVC, with a Wright spirometer was not ideal and the measurement was only made pre-intervention. SVC was measured primarily to demonstrate the lung capacity of the patients and was not considered to be a dependent variable.

In conclusion, the present study shows that active intervention with a combination of OPEP + OIS, using a simple breathing device, provides a clinically useful increase in secretion clearance and that the procedure is both safe and acceptable to intubated patients with high level SCI. This intervention could be used to increase secretion clearance in 
conjunction with MAC or cough assisted devices techniques. Further investigation is warranted of the benefits of regular use of the OPEP + OIS intervention for clinical outcomes.

\section{Data archiving}

The datasets generated and/or analyzed during the current study are available from the corresponding author on request.

Acknowledgements We thank all the patients who participated in this study and the nurse team at the Spine Unit Ward, Medical ICU and the Physical Therapy Teams of Khon Kaen Hospitals for their kindness and support.

Funding Funding was received from the Faculty of Associated Medical Sciences, the Graduate School, Khon Kaen University, and the School of Health Science, Mae Fah Luang University, Thailand.

Author contributions SK collected and analyzed the data and wrote the first draft of the manuscript. CUJ conceived and designed the project and was responsible for preparation of the final manuscript. Both WR and PD helped in study design, the recruitment of participants and were responsible for the clinical care of the patients. DAJ reviewed and helped in the preparation of the final manuscript.

\section{Compliance with ethical standards}

Statement of ethics We certify that all applicable institutional and governmental regulations concerning the ethical use of human volunteers were followed during the course of this research which was approved by the Khon Kaen University and Khon Kaen Hospital Ethics Committees for Human Research. The patients were fully informed before being enrolled and gave their consent verbally and with a finger print on the consent form.

Conflict of interest Dr. Ubolsakka Jones is an academic advisor to the company distributing BreatheMAX. The remaning authors declare that they have no conflict of interest.

\section{References}

1. Arora S, Flower O, Murray NPS, Lee BB. Respiratory care of patients with cervical spinal cord injury: a review. Crit Care Med. 2012;14:64-73.

2. Hutchinson D, Whyte K. Neuromuscular disease and respiratory failure. Pract Neurol. 2008;8:229-37.

3. Reid WD, Brown JA, Konnyu KJ, Rurak JME, Sakakibara BM. Physiotherapy secretion removal techniques in people with spinal cord injury: a systematic review. J Spinal Cord Med. 2010;33:353-70.

4. Rogers WK, Todd M. Acute spinal cord injury. Best Pract Res Clin Anaesthesiol. 2016;30:27-39.

5. van der Schans CP, Postma DS, Koëter GH, Rubin BK. Physiotherapy and bronchial mucus transport. Eur Respir J. 1999;13:1477-86.

6. Volpe MS, Adams AB, Amato MBP, Marini JJ. Ventilation patterns influence airway secretion movement. Respir Care. 2008;53:1287-94.
7. Evans CM, Koo JS. Airway mucus: the good, the bad, the sticky. Pharmacol Ther. 2009;121:332-48.

8. Chicayban LM, Zin WA, Guimarães FS. Can the Flutter Valve improve respiratory mechanics and sputum production in mechanically ventilated patients? A randomized crossover trial. Heart Lung. J Crit Care. 2011;40:545-53.

9. Gil-Perotin S, Ramirez P, Marti V, Sahuquillo JM, Gonzalez E, Calleja I, et al. Implications of endotracheal tube biofilm in ventilator-associated pneumonia response: a state of concept. Crit Care Lond Engl. 2012;16:R93.

10. Jones CU, Kluayhomthong S, Chaisuksant S, Khrisanapant W. Breathing exercise using a new breathing device increases airway secretion clearance in mechanically ventilated patients. J Crit Care. 2013;42:177-82.

11. Branson RD. Secretion management in the mechanically ventilated patient. Respir Care. 2007;52:1328-42.

12. Berlly M, Shem K. Respiratory management during the first five days after spinal cord injury. J Spinal Cord Med. 2007;30: 309-18.

13. Clinkscale D, Spihlman K, Watts P, Rosenbluth D, Kollef MH. A randomized trial of conventional chest physical therapy versus high frequency chest wall compressions in intubated and nonintubated adults. Respir Care. 2012;57:221-8.

14. King M, Phillips DM, Gross D, Vartian V, Chang HK, Zidulka A. Enhanced tracheal mucus clearance with high frequency chest wall compression. Am Rev Respir Dis. 1983;128:511-5.

15. McCarren B, Alison JA. Physiological effects of vibration in subjects with cystic fibrosis. Eur Respir J. 2006;27:1204-9.

16. Darbee JC, Kanga JF, Ohtake PJ. Physiologic evidence for highfrequency chest wall oscillation and positive expiratory pressure breathing in hospitalized subjects with cystic fibrosis. Phys Ther. 2005;85:1278-89.

17. Lee AL, Burge AT, Holland AE. Airway clearance techniques for bronchiectasis. Cochrane Database Syst Rev. 2015;23: CD008351.

18. Thompson CS, Harrison S, Ashley J, Day K, Smith DL. Randomised crossover study of the Flutter device and the active cycle of breathing technique in non-cystic fibrosis bronchiectasis. Thorax. 2002;57:446-8.

19. Tambascio J, de Souza LT, Lisboa RM, Passarelli R, de CV, de Souza HCD, et al. The influence of Flutter ${ }^{\circledR}$ VRP1 components on mucus transport of patients with bronchiectasis. Respir Med. 2011;105:1316-21.

20. Falk M, Kelstrup M, Andersen JB, Kinoshita T, Falk P, Støvring $\mathrm{S}$, et al. Improving the ketchup bottle method with positive expiratory pressure, PEP, in cystic fibrosis. Eur J Respir Dis. 1984;65:423-32.

21. Haukoos JS, Lewis RJ. Advance statistics: bootstrapping confidence intervals for statistic with "difficult" distributions. Acad Emerg Med. 2005;12:360-5.

22. Bland JM, Altman DG. Statistics Notes: Bootstrap resampling method. BMJ. 2015;350:h2622.

23. Spapen HD, De Regt J, Honoré PM. Chest physiotherapy in mechanically ventilated patients without pneumonia-a narrative review. J Thorac Dis. 2017;9:E44-9.

24. Osman LP, Roughton M, Hodson ME, Pryor JA. Short-term comparative study of high frequency chest wall oscillation and European airway clearance techniques in patients with cystic fibrosis. Thorax. 2010;65:196-200.

25. Pillastrini P, Bordini S, Bazzocchi G, Belloni G, Menarini M. Study of the effectiveness of bronchial clearance in subjects with upper spinal cord injuries: examination of a rehabilitation programme involving mechanical insufflation and exsufflation. Spinal Cord. 2006;44:614-6.

26. Vianello A, Corrado A, Arcaro G, Gallan F, Ori C, Minuzzo M, et al. Mechanical insufflation-exsufflation improves outcomes for 
neuromuscular disease patients with respiratory tract infections. Am J Phys Med Rehabil. 2005;84:83-88.

27. Lange DJ, Lechtzin N, Davey C, David W, Heiman-Patterson T, Gelinas D, et al. High-frequency chest wall oscillation in ALS: an exploratory randomized, controlled trial. Neurology. 2006;67:991-7.

28. Fitzgerald K, Dugre J, Pagala S, Homel P, Marcus M, Kazachkov M. High-frequency chest wall compression therapy in neurologically impaired children. Respir Care. 2014;59:107-12.
29. Nygren-Bonnier M, Wahman K, Lindholm P, Markström A, Westgren N, Klefbeck B. Glossopharyngeal pistoning for lung insufflation in patients with cervical spinal cord injury. Spinal Cord. 2009;47:418-22.

30. Jeong JH, Yoo WG. Effects of air stacking on pulmonary function and peak cough flow in patients with cervical spinal cord injury. J Phys Ther Sci. 2015;27:1951-2.

31. Tamplin J, Berlowitz DJ. A systematic review and meta-analysis of the effects of respiratory muscle training on pulmonary function in tetraplegia. Spinal Cord. 2014;52:175-80. 